\title{
نظرية العقل الخامل أصلها وتطبيقاتها
}

\section{The theory of the passive mind, its origin and applications}

\author{
الباحث/ محمد بن أحمد بن علي آل مريع \\ بكالوريوس شريعة، جامعة الملك خالد، أبها، معلم دراسات إسلامية في مدارس التعليم العام، المملكة العربية

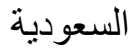

Email: mo.almoraie@gmail.com

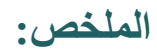

تهدف نظرية العقل الخامل إلى تنشيط العقل الخامل عند الإنسان، وهو عبارة عن مساحة غير مكتشفة في العقل، و هذه النظرية لها أصلين: الأول: هو أنَّ روح الإنسان تنقسم إلى قسمين: (نفس، وعقل)، فعقل الإنسان يدرك الأثياء إن كانت موجودة أو غير موجودة ثم يميز نفعها أو ضررها، ثم تشعر النفس بناءً على تمييز العقل

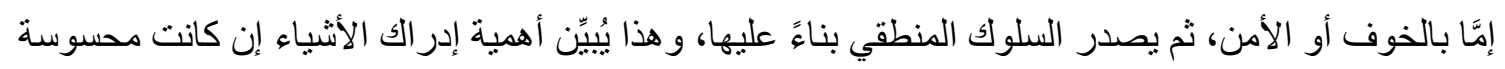
أو غير محسوسة، والأصل الثاني: هو أنَّ عقل الإنسان قادر على إدراك المحسوسات واللا محسوسات على حدٍ الِّاء

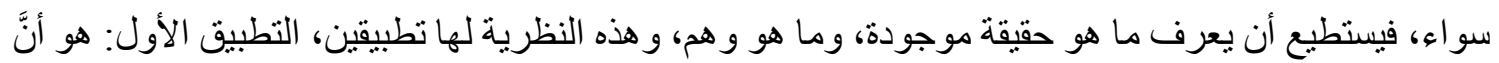
أداة الإنسان لإدر الك اللا محسوسات والغيبيات هو العقل الخامل، وهي قسمين: الأول: ما ورد من الغيبيات في الثر ائع و الكتب السماوية، وهذه تصديقها مسألة إيمان، والثاني: ما ورد عن العلماء في العلوم المختلفة، ويُككن في هذا القسم إدر الك ما هو حقيقة موجودة من هذه الغيبيات و اللا محسوسات، وما هو و هم، وذللك من خلال تنشيط العقل الخامل عبر (مقياس بيان الحقيقة من الوهم) في هذا البحث، وهو من تصميم الباحث، و التطبيق الثاني لهذه النظرية: هو أنَّ تحفيز العقل الخامل أداة الإنسان للإبداع و الابتكار. الكلمات المفتاحية: العقل، الخامل، نظرية، اللا محسوسات، الغيبيات، الإدر اك. 
الهجلة الدولية لنشر البحوث والدراسات

International Journal of Research and Studies Publishing
المجلد الثاني - الإصدار الثامن عشر

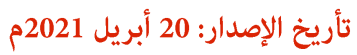

ISSN: 2709-7064

\title{
The theory of the passive mind, its origin and applications
}

\begin{abstract}
:
The theory of the passive mind aims to activate the passive mind in man, which is an undiscovered space in the mind, and this theory has two origins: The first is that the human soul is divided into two parts: (soul and mind), so the human mind perceives things whether they exist or not. They exist and then distinguish their benefit or harm, then the soul feels based on the distinction of the mind, either by fear or security, and then issues logical behavior according to it, and this shows the importance of perceiving things whether they are tangible or imperceptible, and the second principle: is that the human mind is able to perceive the senses and the non Both are tangible, so he can know what an existing reality is, and what is an illusion, and this theory has two applications, The first application: is that the human tool for perceiving the imperceptible and the unseen is the passive mind, and it is of two parts: the first: what is mentioned from the occult in the laws and heavenly books, and this is a matter of faith, and the second: what has been reported about scholars in different sciences, and in this section it is possible to perceive what It is a reality that exists from this unseen and imperceptible, and what is an illusion, by activating the passive mind through (the scale of the statement of truth from illusion) in this research, and it is designed by the researcher, and the second application of this theory: Is that stimulating the passive mind is a human tool for creativity and innovation.
\end{abstract}

keywords: The mind, Inactive, Theory, Imperceptibility, Occult, Perception. 
يمكن للإنسان أن يدرك بعقله الأثياء المحسوسة، التي يسنطيع أن يدركها بوسائل الإدر الك التي هي البصر ،

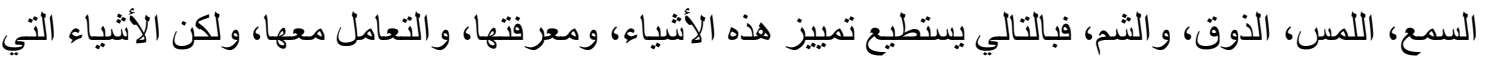

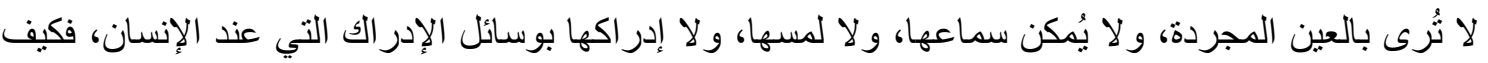
بستطيع شخص أن يجزم بوجودها أو عدمه؟ وقد أكَّد رضا (1975) أنَّ الناس أصناف بالنسبة لهذه الموجودات التي لا يُككن إدر اكها، فمنهم من يدَّعي أنَّهَ

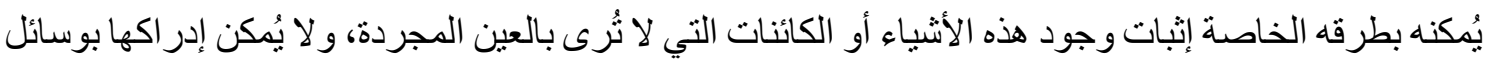

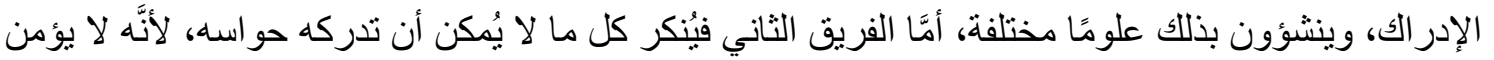

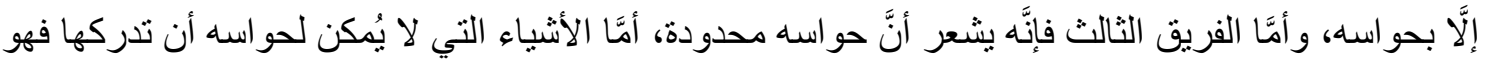

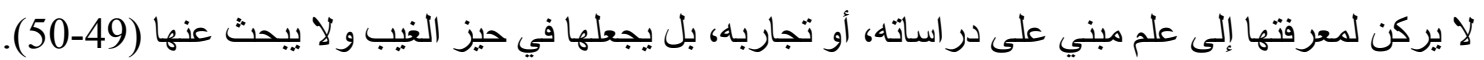
كما يذكر فايل (1981) أنَّهَ حينما تُطرح مسألة لما هو مفارق لمجال الحس عند الإنسان، فإنَّ العقل يستنكف

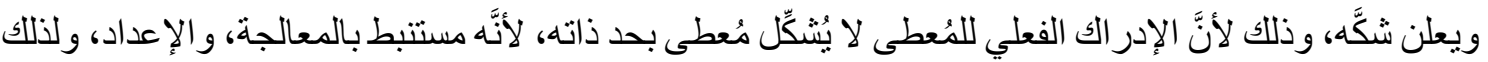

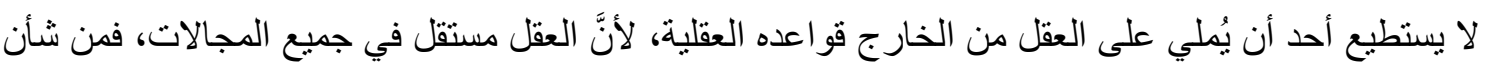

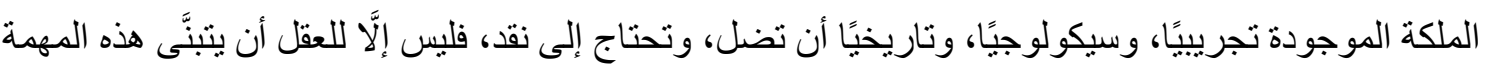

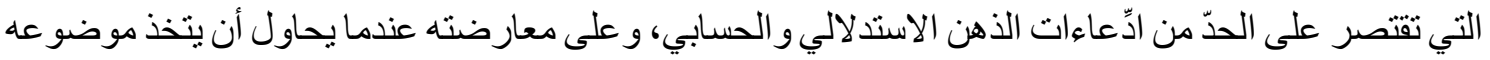

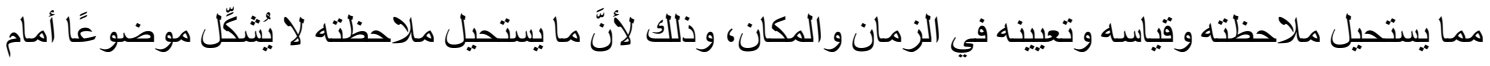
الفكر الذي يريد اكتثاف كل خطاب مترابط عن طريق النحليل الارتدادي، واكتثاف الدفاهيم التي تكونه،

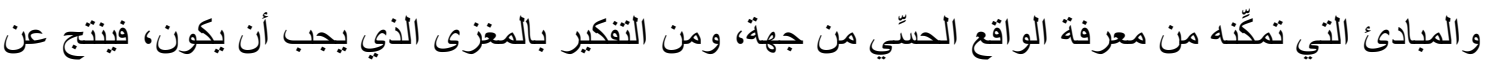
ذلك أنَّ العقل مستقل، وليس كلّّي القدرة، فهو يقدم الدفاهيم و المبادئ الأساسية لكل علم طبيعي مدكن، إلّا أنَّهَ لا

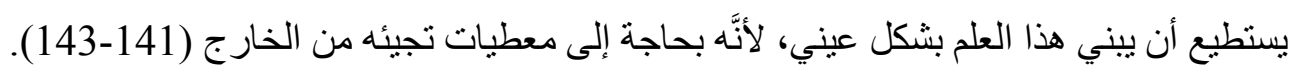
وقد عرض الجندي (2011) من كتاب الغيب والعقل لإلياس بلكا وذلك عندما ختم المؤلف عرضه لبعض آراء أهم الفلاسفة الغربيين في موضوع العقل وطبيعته وحدوده، فأكَّد قصور العقل عن اقتحام كثير من المجالات

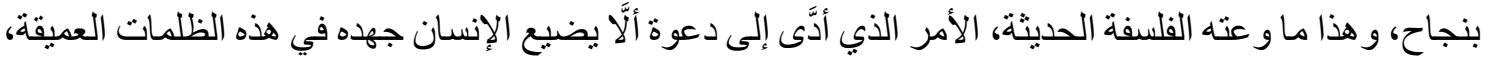

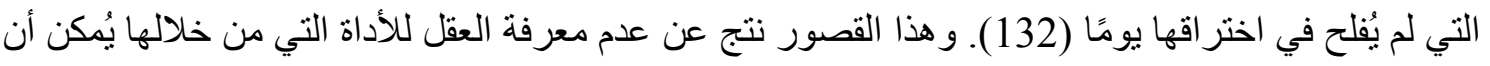
يدرك حقيقة وجود الأمور الغييية من عدمها، وهذه الأداة هي التي سوف ييينها هذا البحث، ويجعلها مقياسًا

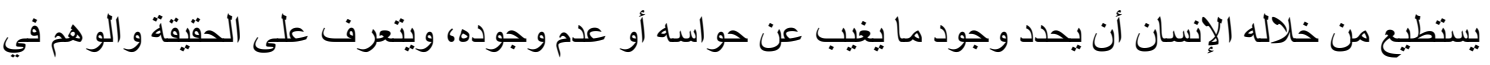
عالم الغييات، وذلك من خلال النظرية الني سيبينها هذا البحث، وهي (نظرية العقل الخامل)، 
و هذا العقل الخامل هو عبارة عن مساحة في عقل الإنسان غير مكتشفة، تُكُّن الإنسان من التفريق بين الحقيقة و الوهم في الأمور الغييية، فهي أداته لإدر اك اللامحسوسات.

مشكنة البحث:

تتمثل مشكلة البحث في عدم التمبيز بين ما هو حقيقة موجودة وما هو مجرد وهم من الغيبيات التي لا يُمكن

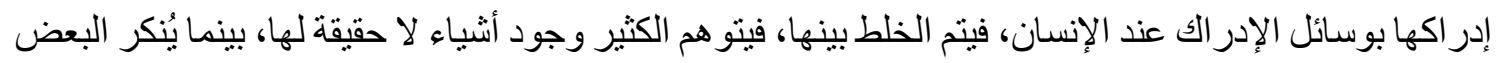
من الغيبيات ما هو حقيقة موجودة، فتأتي هذه النظرية (نظرية العقل الخامل) لتكون أداة لاى الإنسان يميز من خلالها بين ما هو حقيقة موجودة، وما هو وهم وزيف لا حقيقة له من عالم الغيبيات. أهداف البحث:

1) تنتيط العقل الخامل عند الإنسان الذي من خلاله يستطيع أن يدرك ما هو حقيقة موجودة، وما هو و هم وزيف لا حقيقة له من عالم الغيبيات التي لا يُمكن للإنسان أن يدركها بواسطة وسائل الإدر الك المحسوسة. 2) القبط محفز ات العقل الخامل. 3) القدرة على التنبؤ بالسلوك البشري. 4) التعرُّف على القدرات العقلية المستخدمة، و القدر ات العقلية الخاملة عند الإنسان.

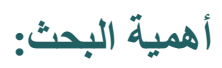
1) أن يميز الإنسان بين الحقيقة والوهم، فيعرف الحقيقة فيتعامل معها، ويعرف الوهم فيحفظ وقته وجهده من العبث من خلال البحث عن شيءٍ لا وجود له. 2) أن يتعرَّف الإنسان على محفز ات عقله الخامل. 3) أن يتعرَّف الإنسان على مقدار القدرات العقلية التي يحتاجها في كل موقف. مصطات البحث:

العقل: الغريزة التي في الإنسان، والتي يمتاز بها عن سائر الحيوان، فبها يعلم، وبها يعقل، وبها يميز، وبها يقصد المنافع دون المضار (صوفي، 2003، 360). يعرّف الباحث العقل الخامل: بأنَّه مساحة في العقل غير مكتشفة، الأمر الذي أدَّى إلى خمولها، وهذه المساحة هي الأداة التي من خلالها يُمكن للإنسان إدر الك ما هو حقيقة موجودة، وما هو وهم وزيف لا حقيقة له من الغيبيات التي لا يُمكن للإنسان أن يدركها من خلال وسائل الإدر الك المحسوسة.

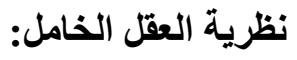
أولًا: الأصل في نظرية العقل الخامل: 


$$
\text { و هذه النظرية لها أصلان، هما: }
$$

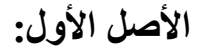

و هو أنَّ عقل الإنسان قادر على إدر اك المحسوسات، و اللا محسوسات و الغيبيات على حدٍ سو اء، فيعرف ما هو موجود حقيقةً، وما هو مجرد و هم لا حقيقة له، و إن كان العقل لا يستطيع معرفة صفة وكنه الأشياء الغيبية، ولكنه قادر على إدر الك حقيقة وجودها من عدمه.

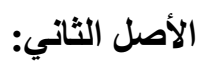

و هو أنَّ السلوك الصادر من الإنسان بصدر نتيجة إدر اك العقل للشيء، ثم التمييز له، ثم شعور النفس تجاه

$$
\text { هذا الثيء، وبناءً على ذلك فإنَّ روح الإنسان تنقسم أصلًا إلى قسمين، وهما: }
$$

1) النفس: و هي التي بها يكون جسد الإنسان حي، فيأكل، ويشرب، ويذهب، ويجيء، ويُسَّى فلان، وبها يجزع

$$
\text { الإنسان، ويطمئن، ويخاف، ويأمن، فوظيفتها المشاعر التي بها يُحس الإنسان. }
$$

2) العقل: به بستطيع الإنسان الإدر الك، و التمبيز ، فبدرك حقائق الأمور، ويميز ها، فإذا أدرك أمر به خطر خافت الهبه

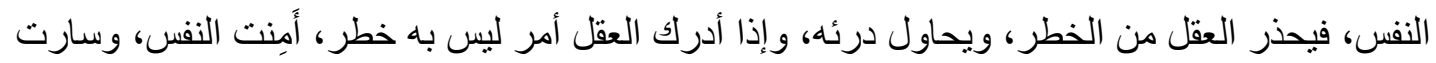

$$
\text { الحياة بشكلٍ طبيعي. }
$$

فمن خلال هذا التقسيم تبيَّن أن وظيفة العقل الذي ينتج عنها السلوك البشري هو الإدر اك ثم التمبيز، ووظيفة النفس المشاعر بناءً على تمبيز العقل، ثم بعد ذللك يصدر فعل الإنسان بناءً عليها، فعلى سبيل المثال إذا رأى هُ الإنسان حريق، فإنَّ عقله يُدرك أنَّها حارَّة ومُحرقة، ويخرج منها دخان يمنع من التنفس بشكل طبيعي،

$$
\text { ويسبب الاختناق، فُمُيز العقل أنَّها خطر، وضرر، فتخاف النفس من وقوع الجسد فيها، }
$$

فيصدر فعل الإنسان بعد ذلك بناءً على شعور النفس، وتمييز العقل فيهرب من النار، ومن مصدر الحريق،

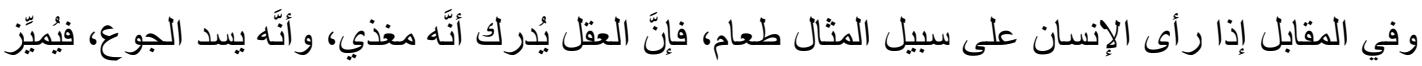
العقل أنَّه نافع، فتأمن النفس، فيصدر فعل الإنسان بعد ذلك بناءً على شعور النفس، وتمييز العقل فيتناول هذا الطعام، و الثكل التالي يوضِّح هذا السلوك البشري: 


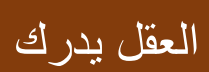

حقيقة - وهم
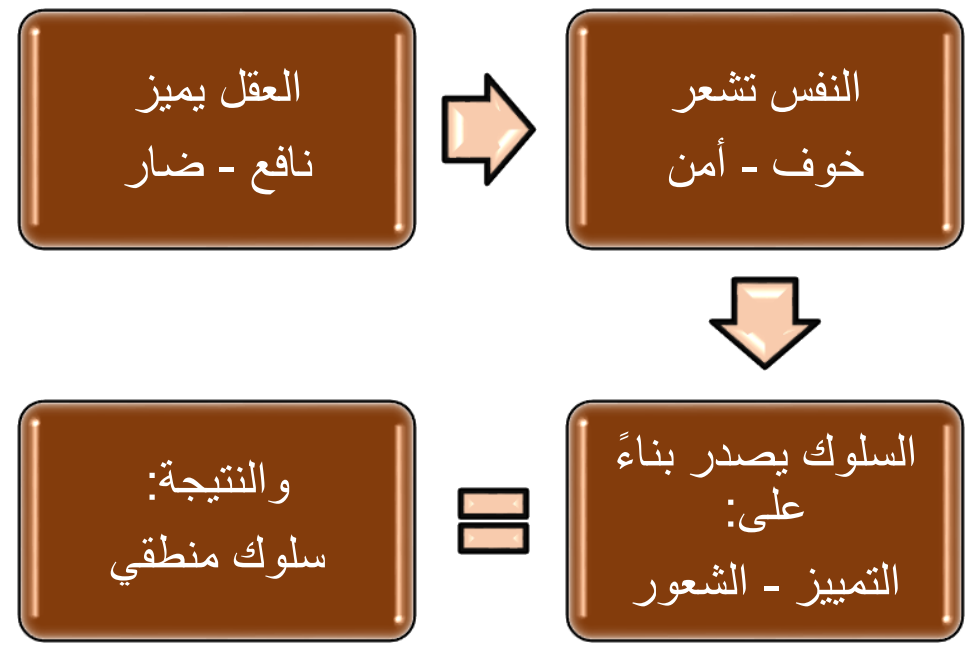

فمن خلال هذا الثنكل نبيَّن أنَّ النفس و العقل هما أقسام الروح، لأنَّ السلوك البشري تجاه الثيء الذي أدركه العقل نتج عن تمبيز العقل ثم شعور النفس، وتبيَّن أيضًا أهمية الإدر الك، لأنَّه الأصل في السلوك البشري، ومن لهن هذا المنطلق جاءت هذه النظرية لكي تُعطي الإنسان الأداة التي من خلالها يُدرك الأشياء الغيبية، و غير المحسوسة، فيميز بين ما هو حقيقة منها، وما هو وهم، لكي يصدر السلوك البشري بعد ذلك بشكل منطقي، بدون مبالغة، فيُّرك الإنسان ما هو حقيقة موجودة من الغيييات، و اللا محسوسات، ثم يُميز ما هو نافع، وما هو ضار ، لكي بهي

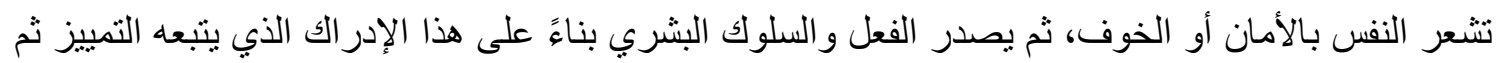
الثعور.

\section{ثُانيًا: خصائص العقل الخامل:}

إنَّ تنشيط هذا العقل الخامل عند الإنسان يعطيه مجمو عة من الميزات، وهي كما يلي:

1) أنَّ تنشيط العقل الخامل يُكسب الإنسان الأداة التي من خلالها يستطيع أن يدرك الأثياء الغير محسوسة. 2) أنَّ تنشيط العقل الخامل يجعل الإنسان يُفرق بين الحقبقة والوهم.

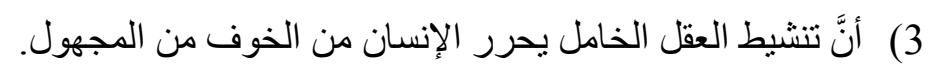
4) أن تنشيط العقل الخامل يفتح للإنسان مدارك و آفاق أوسع، ومجالات أرحب للتفكير. 5) أنَّ تنشيط العقل الخامل يساعد الإنسان في أن تكون تصرفاته منطقية، ويستطيع أن يفسّر ها العقل البشري،

$$
\text { الأمر الذي يجعل الإنسان ينبذ الخر افة، وييتعد عن الأوهام. }
$$

6) أنَّ تتشيط العقل الخامل بحلق بالإنسان في سماء الإبداع، ويحقق له الكثبر من الفرص في الحياة، وذلك من الإن خلال الأفكار التي من الممكن أن ينتجها. 
الهجلة الدولية لنشر البحوث والدراسات

International Journal of Research and Studies Publishing
المجلد الثاني - الإصدار الثامن عشر تأريخ الإصدار: 20 أبريل 2021م

ISSN: 2709-7064

7) أنَّ العقل الخامل يحتاج إلى محفز ات لكي يعمل، فيفكر ، يحلل، يستنتج، وييتكر.

ثالثًا: وظائف عقل الإنسان:

يُمكن تقسيم وظائف عقل الإنسان إلى قسمين، وهذا بحسب الحاجة إليها، و هي كما يلي:

1) وظائف عقل الإنسان من حيث إصدار السلوك، هي:

$$
\begin{aligned}
& \text { • . الإدرالك. } \\
& \text { • التمييز. }
\end{aligned}
$$

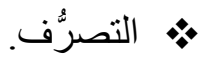

2) وظائف عقل الإنسان من حيث الابتكار، و الإبداع، هي:

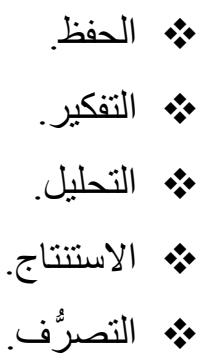

فمن خلال التقسيم السابق لوظائف العقل نجد أنَّ التصرُّف وظيفة أساسية في كلا التقسيمين، لأنَّه هو النتيجة

$$
\begin{aligned}
& \text { للقدر ات العقلية عند الإنسان. } \\
& \text { رابعًا: أقسام العقل: } \\
& \text { ينقسم العقل إلى قسمين، و هما: }
\end{aligned}
$$

1) العقل النَّظط: وهذا القسم من العقل هو الذي يستطيع إدراك الأشياء المحسوسة، التي يستطيع أن يدركها بحواسه، وبوسائل الإدراك التي عنده، التي هي السمع، البصر، اللمس، الذوق، و الثم، فيعرف ما هو نافع منها، وما هو ضار، مثل: القلم، الورقة، الكتاب.....إلخ، وكل الأشياء التي بسنطيع الإنسان رؤيتها فإنَّه يدركها من خلال البصر فيدركها، ويتعامل معها، ومثل: الموسيقى، صوت موج البحر....إلخ، يسنطيع الإنسان إدر اكها من خلال السمع، فيدرك هذه الأصوات ولو لم برى مصدر ها، وهكذا في جميع

$$
\text { الأشياء المحسوسة. }
$$

وكذلك فإنَّ العقل النَّنط عند الإنسان هو الذي يستخدمه أكثر الناس في حياتهم اليومية الروتينية عندما يذهبون، ويجيئون، ويأكلون، ويشربون، و عندما يمارسون حياتهم بشكلٍ طبيعي. 2) العقل الخامل: و هذا القسم من العقل خامل لا يعمل في الأغلب، ومن هنا جاءت تسميته لأنَّ الإنسان لم يكتشف هذا الجزء من عقله، 
الهجلة الدولية لنشر البحوث والدراسات

International Journal of Research and Studies Publishing
المجلد الثاني - الإصدار الثامن عشر

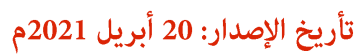

ISSN: 2709-7064

ولم يعرف محدداته، كما أنَّه يستخدمه في بعض المو اقف دون أن يشعر بقدر اته التي تمكنه من إدر الك كل ما هو موجود سو اءً أكان محسوسًا، أم غير محسوس، فمن خلال هذا الجزء من العقل يستطيع الإنسان أن يدرك ما هو حقيقة موجودة، وما هو زيف ووهم، من الغيبيات.

كما أنَّ الإنسان يستخدم عقله الخامل في بعض المو اقف في حياته، عندما يستجد عنده أمر، أو يحصل خلل في حياته، أو يسعى لتحقيق طموح، أو يتغلب على منافسين، و الثنكل التالي يبين تقسيم العقل:

أقسام العقل بناءً على الإدر الك

العقل النشط الذي بدرك

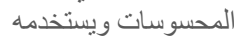
الإنسان في حياته الطبيعية $\%$ \%

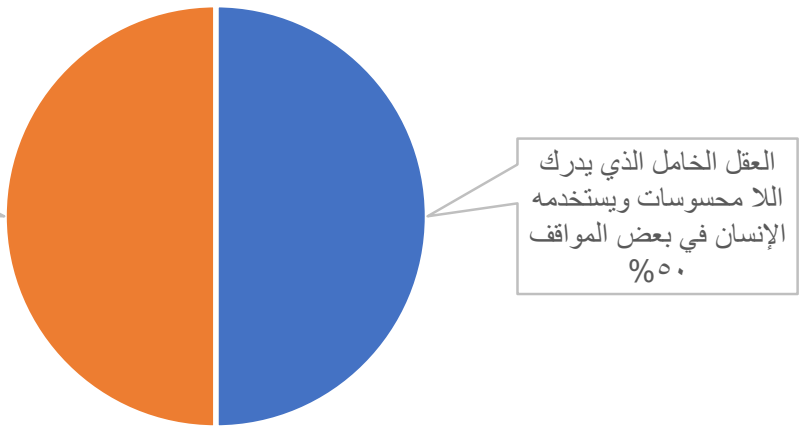

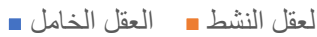

فتنبيَّن معنا من خلال الثكل السابق أنَّ العقل بإمكانه أن يدرك المحسوسات و اللا محسوسات، بل إنَّه بإمكان

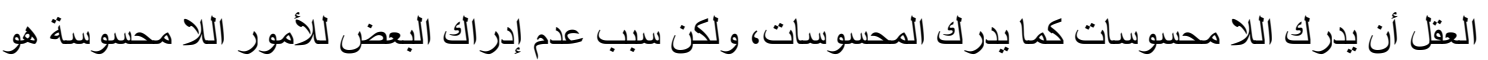
أنَّ العقل الخامل لديه غير منشَّط، فلا يستطيع إدراك اللا محسوسات، ولا يعرف كيف يستخدم الإنسان عقله الخامل ليدرك اللا محسوسات، وبناءً على هذا نستطيع تقسيم العقل إلى قسمين: نشط، وخامل، وكل قسم له نصف العقل، لأنَّ العقل يستطيع إدر الك المحسوسات و اللا محسوسات على حدِّ سو اء.

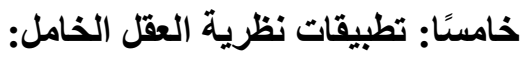
يُمكن نطبيق نظرية العقل الخامل كما يلي: التطبيق الأول: إدراك الغيبيات والغير محسوسات:

يملك العقل الخامل القدرة على إدر الك الغيبيات، و اللا محسوسات، وهو الأداة التي يستطيع الإنسان من خلالها

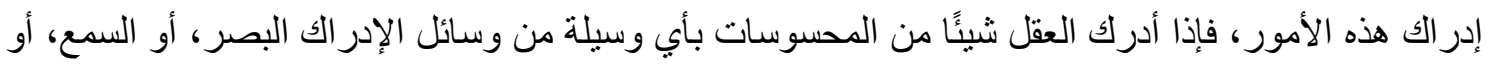

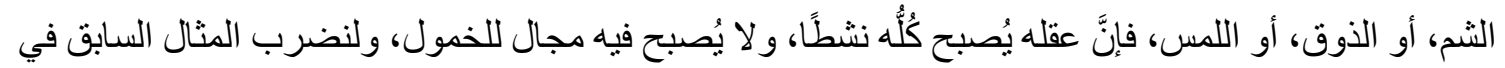
الحريق، فإذا حصل حريق، أدركها عقل الإنسان من خلال البصر ، فميَّز خطر ها، فهرب منها، فلم يبقى في عقل الإنسان نقطة عمياء، أو جهة مجهولة في هذا الموضوع، فيصبح عقل الإنسان بالثكل التالي: 
الهجلة الدولية لنشر البحوث والدراسات International Journal of Research and Studies Publishing

ISSN: 2709-7064
الهجلد الثاني - الإصدار الثامن عشر تأريخ الإصدار: 20 أبريل 2021م

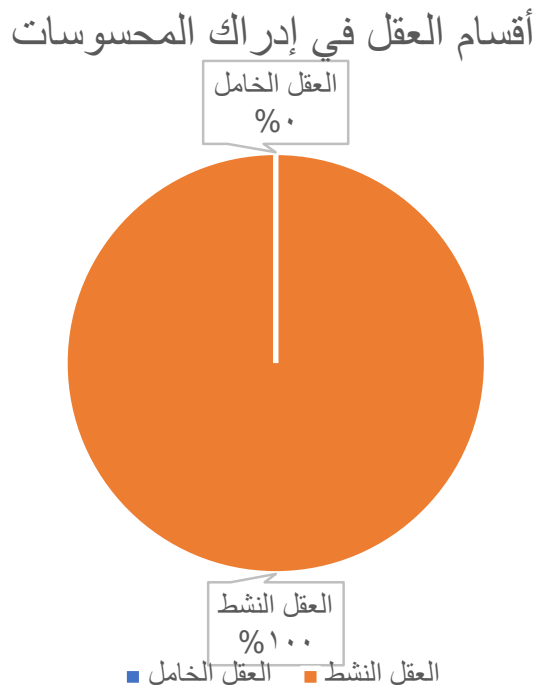

و إذا كان هناك شيء من اللا محسوسات لم يستطيع عقل الإنسان إدر اكه فإنَّ الإنسان لا يستطيع التعامل معه، و هنا يعتمد الإنسان على أي كلام يُقال عن هذا الثيء، كالغريق الذي يتمسك حتى بالقشة لينجو ، فعلى سبيل المنال في الجن، فهم عالم غيبي، والإنسان الذي لم يسنطع إدر الك هذه الحقبقة وكيفيتها فإنَّهُ يُصدِّق أي كلام يُقال عنها، و هنالك صنف من الناس ينكرها، و هذا التباين سببه عدم معرفة كيفية إدر اك هذا الأمر، وفي هذه الحالة يُصبح عقل الإنسان كما في الثنكل التالي:

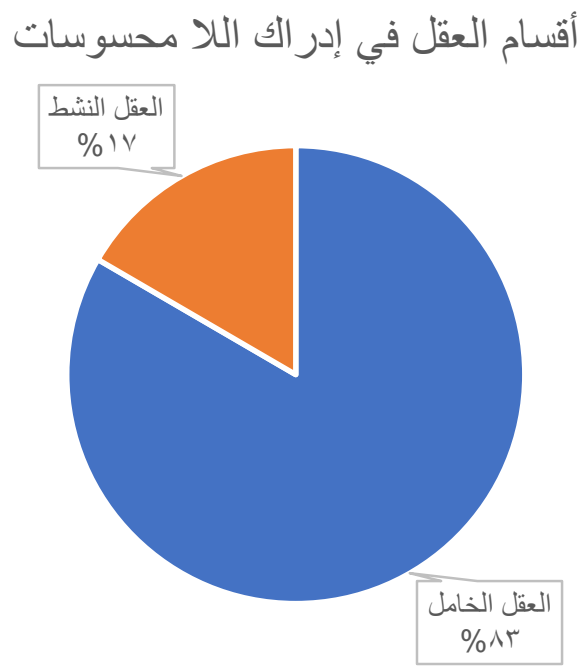

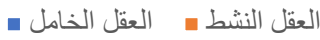

فيتبين معنا من خلال الثكل السابق أنَّ عقل الإنسان الخامل في هذه الحالة مقداره 84\%، و عقله النشط هو فقط 16\%، ومن خلاله إمَّا أن يتبع أي تعليمات وتوجيهات تأتيه ممن يدَّعي معرفة هذا الثيء اللا محسوس 
المجلة الدولية لنشر البحوث والدراسات

International Journal of Research and Studies Publishing
المجلد الثاني - الإصدار الثامن عشر

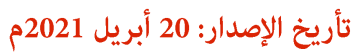

ISSN: 2709-7064

و هو غير مدرك لحقيقة ما يعطله، أو ينكره بلا دليل، ويز عم أنَّهَ وهم، وهو غير مدرك حتى لما يقول، لأنَّه يقوله من باب العجز عن الإدر اك لهذا الثيء الغيبي، أو اللا محسوس.

وقد توصلت إلى هذه النسبة من خلال حسبة بدائية بسبطة، وبيانها كما يلي:

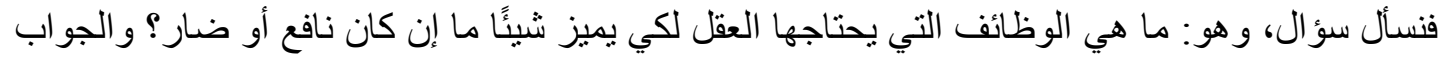
على هذا السؤال أقول: يحتاج الإنسان إلى ثناث وظائف لكي يتخذ القرار بشأن أمرٍ ما، سواءً أكان غيبيًا لا محسوسًا، أو كان أمرًا محسوسًا، وهي (الإدر الك، ثم التمبيز، ثم يصدر التصرُف)، وبناءً على تقسيم العقل إلى لى (نشط، وخامل)، و أنَّ العقل النشط يدرك المحسوسات، فلذلك له الثناث الوظائف نفسها لكي يتخذ القرار ويصدر عنه السلوك المنطقي، وهي: (الإدراك، ثم التمبيز، ثم يصدر التصرُّ)، و العقل الخامل يدرك اللا محسوسات فلذلك له الثلاث الوظائف نفسها لكي يتخذ القرار ويصدر عنه السلوك المنطقي، وهي: (الإدر الك، ثم التمبيز، ثم يصدر التصرُّف)، فإذا العقل النشط يُشنكل 50\% من عقل الإنسان، والعقل الخامل يثكل 50\% كذلك من عقل الإنسان، و إذا قنَّمنا الـ 50\% من كل عقل إلى ثلاثة أقسام، وهي الثلاث وظائف للسلوك المنطقي (الإدر الك، و التمييز، و التصرف)، فنقسم 50٪3=16.6، فإذًا يكون للثلاث الوظائف لكل وظيفة (16.6\%) من القدرات العقلية، فإذا لم يستطع الإنسان إدر الك الثيء اللا محسوس فتعطَّلت حينهاوظيفة من وظائف العقل النشطو الخامل، و هي الإدر الك، فيصبح العقل في هذه الوظيفة خامل، فإذا تعطَّل الإدراك تعطَّل حينها التمبيز، وفي هذه الحالة تتعطل وظيفتين في العقل النشط، و العقل الخامل،

وبما أنَّ كل وظيفة لها 16.6\% من القدرات العقلية فحينها نحسبها بالثكل التالي:

$$
\begin{aligned}
& \text { وظائف العقل النشط: الإدر الك= (16.66\%)، التمييز=(16.66\%)، التصرف= (16.66\%). } \\
& \text { وظائف العقل الخامل: الإدر اك= (16.66\%)، التمبيز= (16.66\%)، التصرف= (16.66\%). }
\end{aligned}
$$

وفي هذه الأثناء لم بدرك عقل الإنسان النشط شيء فتتعطل عنده وظبفتي الإدر اك، والتمبيز في هذا القسم، ولم يدرك عقل الإنسان الخامل شيء فحينها تتعطل عنده وظيفتي الإدراك، و التمبيز في هذا القسم، وحينها لم يدرك العقل شينًا إدر اكًا تامَّا، فلم يستطع تمييزه، فحينها يخسر من قدر اته العقلية ما مقداره (66.66\%)، وذللك بجمع القدر ات العقلية للوظائف المعطلة، وبما أنَّ العقل الخامل لم يدرك، فلم يميز، فحينها تتعطل وظيفة التصرف المنطقي عنده، فيخسر الإنسان أيضًا ما مقداره (16.66\%) لوظيفة التصرف، فنجمعها مع القدرات المعطلة و هي (66.66\%)، فيُصبح المجموع= (83\%) من القدرات العقلية المعطلة، وحينها يتبقَّى للإنسان فقط (17\%) (17)

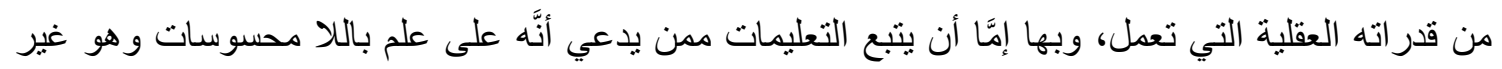
مدرك لما يعطله، وحينها يقع الإنسان في الو هم و الخر افة، أو ينكر هذه اللا محسوسات من غير دليل، وحينها يقع الإنسان في الجهل. 


\section{خصائص الأمور الغيبية أو الغير محسوسة:}

الأمور الغيية أو الغير محسوسة لها خصائص، أوردها فيما يلي:

$$
\text { 1) أنَّ الإنسان لا يستطيع أن يدركها بحو اسه المجردة. }
$$

2) أنَّ الإنسان بستطيع إدر اكها بعقله فقط.

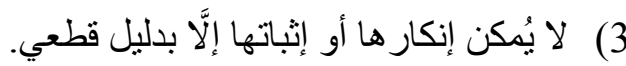

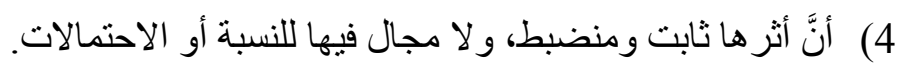

5) أنَّ أثرها دالّّ عليها، ويشترط لهذا الأثر لتكون دلالته قطعية على وجود هذا الثنيء اللاد محسوس ثلاثة

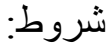

$$
\begin{aligned}
& \text { أ- أن يكون الأثر ثابت. } \\
& \text { بـ أن يكون الأثر منضبط. } \\
& \text { ج- أنَّ هذا الأثر غير قابل للنسبة والاحتمالات. }
\end{aligned}
$$

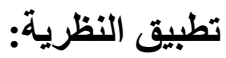

الأمور الغييية وغير المحسوسة لهاطريقين لإدر اكها، ومعرفة ما إن كانت حقيقة أو وهم، والأداة لهذا الإدر اكك

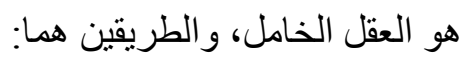

1) أن يأتي الخبر عن هذه المغيبات وغير المحسوسات في الثر ائع والكتب السماوية، وفي هذه الحالة يكون

$$
\text { التصديق بها مسألة إيمان. }
$$

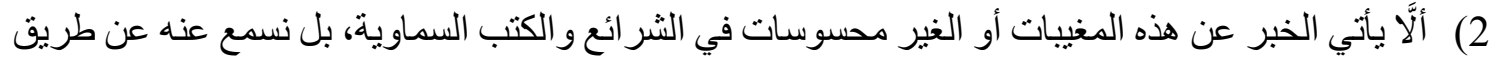

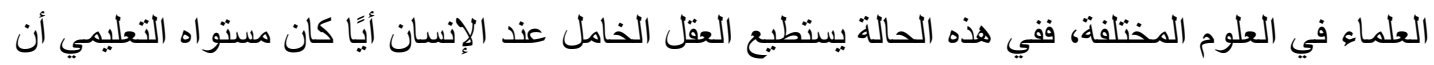

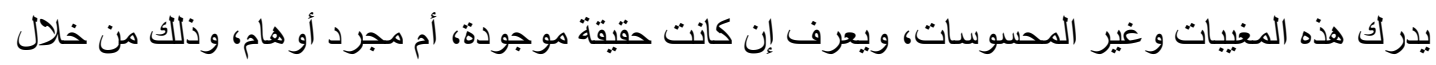

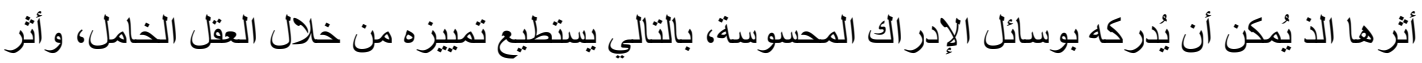
هذه المغيات يجب أن يكون ثابت، منضبط، و لا مجال فيه للنسبة والاحتمالات، فعلى سبيل المثال (التيار

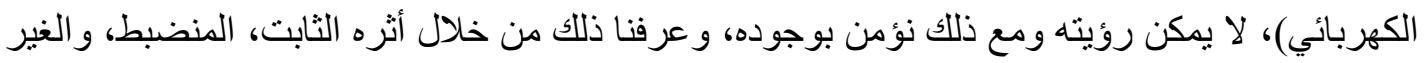

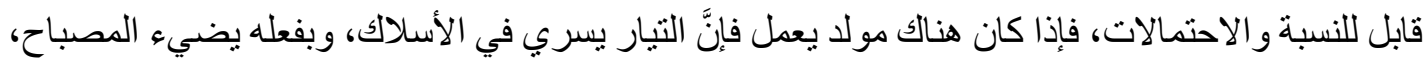

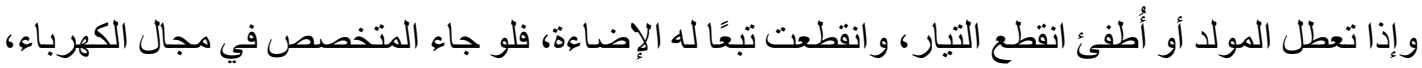
وقال لا تلمس الأسلاك المكثوفة أثناء سريان التبار الكهربائي فيها، بعني في أثناء عمل المولد، لأنَّ هذا التنار سوف يحرق الجسم، ولأنَّ هذا التيار بسبب التماس للأجسام المكثوفة إذا كانت ناقلة للتيار الكهربائي،

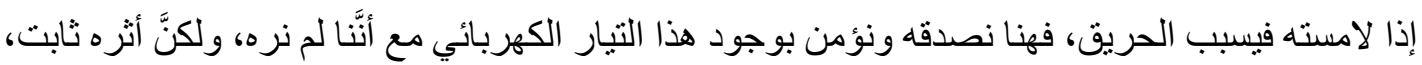

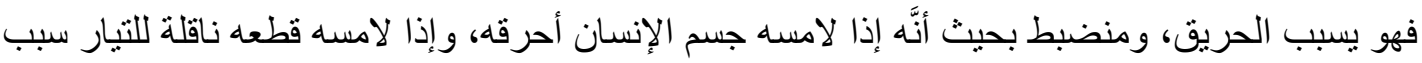
الالتماس، وكذلك فإنَّ هذا الأثر غير قابل للنسبة والاحتمالات، 
الهجلة الدولية لنشر البحوث والدراسات

International Journal of Research and Studies Publishing
المجلد الثاني - الإصدار الثامن عشر

تأريخ الإصدار: 20 أبريل 2021م

ISSN: 2709-7064

فلا يمكن أن يقول قائل إذا لامس الإنسان التيار الكهربائي بيده فاحتمال أن يحرقه، واحتمال ألَّ يحرقه، وكذلك أثره ثابت وهو إضاءة المصباح، ومنضبط فإذا وُجد التبار وُجدت الإضـاءة وبالعكس، وهذا الأثر غير قابل للنسبة والاحتمالات، فلا يستطيع أحد أن يقول: إذا وُجد التيار قد توجد إضـاءة وقد لا توجد، فبهذا نؤمن بوجود التيار الكهربائي، لأنَّ أثره ثابت، منضبط، و غير قابل للنسبة والاحتمالات، ونأخذ مثالاً آخر ، فأقول: بيانات الإنترنت في جهاز الكمبيوتر ، والأجهزة الذكية، فإذا كانت البيانات تعمل فإنَّ الإنسان بستطيع أن يتصفح في جهازه عبر الثبكة العنكبونية، ويتابع الأخبار من كل مكان، ويتابع الوسائط، ويستطيع تنزيل الملفات، وغير ها من الخدمات المعروفة، فإذا أُغلقت البيانات، أو انقطعت لا يسنطيع الإنسان أن يحصل على الخدمات السابقة عبر جهازه، فهذا أثر ثابت وهو الاتصال، ومنضبط بحيث إذا وُجدت البيانات وُجد الاتصال، و إذا انقطعت البيانات انقطع الاتصال، وهذا الأثر غير قابل للنسبة والاحتمالات قلا بستطيع أن وهان

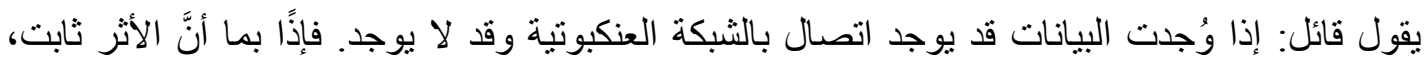
منضبط، و غير قابل للنسبة و الاحتمالات فهنا نؤمن بوجود شيء اسمه البيانات مع أنَّا لم نر ها، ولم نلسهها،

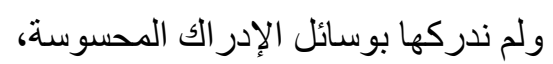

بل آمنا بوجودها بو اسطة العقل الخامل عندما نَّ تتشيطه، و على هذه الأمثلة فقس جميع الغيبيات، و الغير محسوسات، ويمكن أن أوضحها في الثكل التالي: 
الهجلة الدولية لنشر البحوث والدراسات

International Journal of Research and Studies Publishing
المجلد الثاني - الإصدار الثامن عشر تأريخ الإصدار: 20 20 2021 2021م

ISSN: 2709-7064

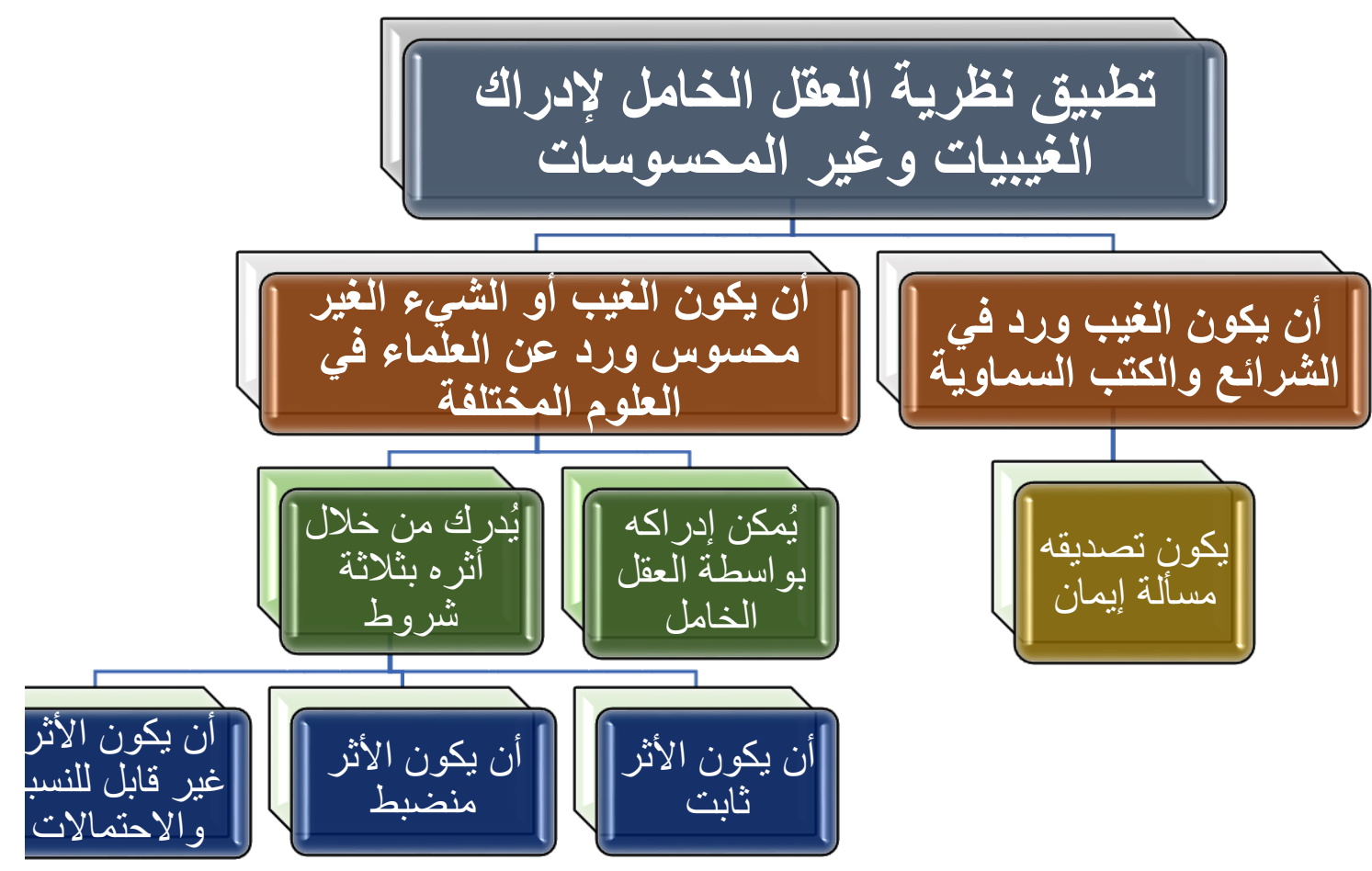

وبالنسبة للغيبيات التي وردت في الثر ائع والكتب السماوية فيكون تصديقها مسألة إيمان، و أمَّا ما ورد من الغيبيات و غير المحسوسات عن العلماء في العلوم المختلفة فإنَّهَ يُمكن قياسه للتأكد من حقيقة وجوده من عدمه، وله ومن خلال الثكل السابق يُمكن عمل المقياس التالي لإدر الك الغيبيات و الغير محسوسات، ومعرفة ما هو حقيقة موجودة منها، وما هو مجرد و هم لا حقيقة له من خلال (مقياس بيان الحقيقة من الوهم):

\begin{tabular}{|c|c|c|c|}
\hline ע & تمعم & العبارة & م \\
\hline & & هذا الثيء الغيبي و الغير محسوس له أثر محدد. & 1 \\
\hline & & هذا الثيء الغيبي و الغير المحسوس يُُكن إدر اكك أثره بوسائل الإدر اك الدحسوسة. & 2 \\
\hline
\end{tabular}




\begin{tabular}{|c|c|c|c|}
\hline & & 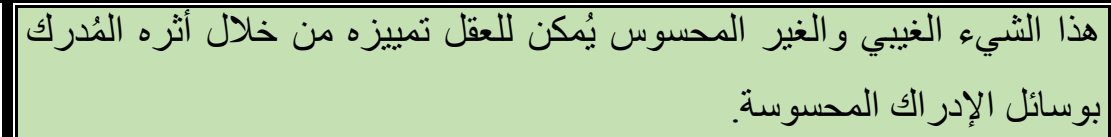 & 3 \\
\hline & & هذا الثيء الغييي و الغير المحسوس يُمكن منع أثره بإرادة الإنسان في أي وقت. & 4 \\
\hline & & لهذا الثنيء الغيبي والغير المحسوس يُكن للإنسان التحكّم في أثره. & $\overline{5}$ \\
\hline & & هذا الثيء الغيبي و الغير محسوس إذا وُجد وُجد أثره و إذا انعدم انعدم أثره. & 6 \\
\hline
\end{tabular}

وحيث أنَّ العبارة الأولى والثانية و الثالثة تبيّن أنَّ أثثر هذا الثيء الغيبي والغير محسوس ثابت لأنَّ أثثره محدد،

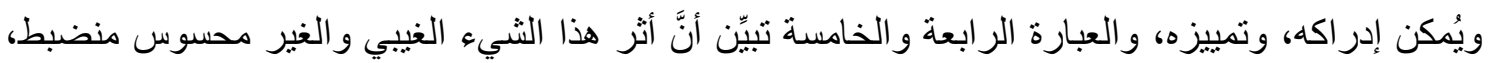

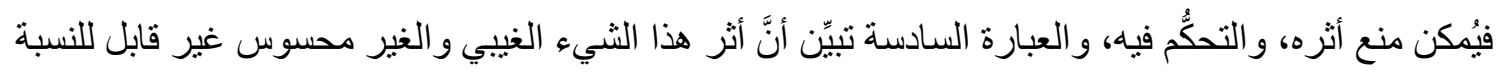
و الاحتمالات، حيث أنَّه إدا وُجد هذا الثنيء الغيبي و الغير محسوس وُجد أثره، و إذا انعدم انعدم أثره معها، وبالتالي

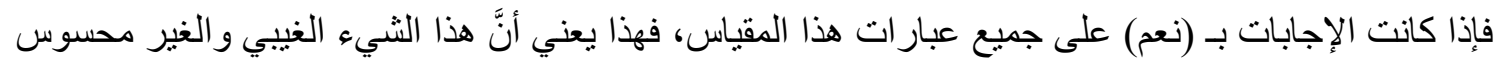

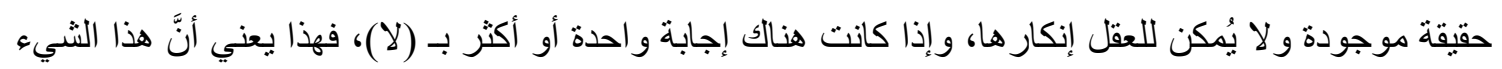
الغيبي و الغير محسوس مجرد و هم لا حقيقة له، فإذا كانت الإجابة بـ (لا) في العبارة الأولى أو الثانية أو الثالثة،

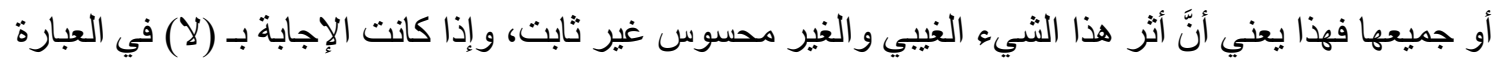

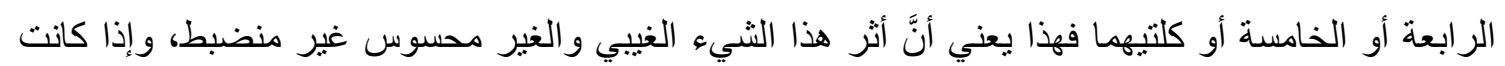

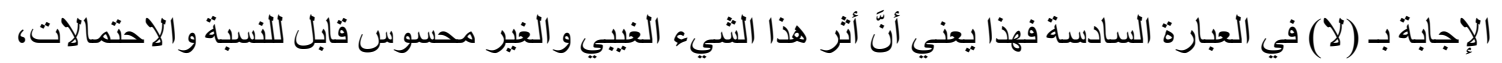
وبالتالي لا تنطبق عليه شروط النظرية، فيكون الحديث عنه خر افة من الخرافات، لأنَّه في هذه الحالة يكون الحديث عن هذا الثيء الغيبي و الغير محسوس غير منطقي، و لا يُكن للعقل إدر اكه، و لا تمييزه.

\section{التطبيق الثاني: المحفزات للإبداع والابتكار:}

يعيش الإنسان حياته وفق روتين محدد، فإذا اختلف عليه الروتين، أو حصلت له معاناة كانت بمثابة محفز

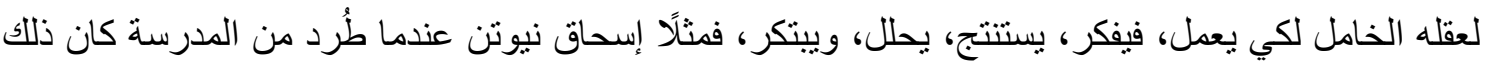

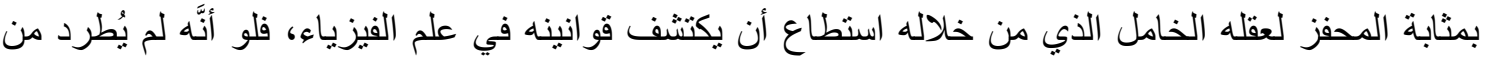

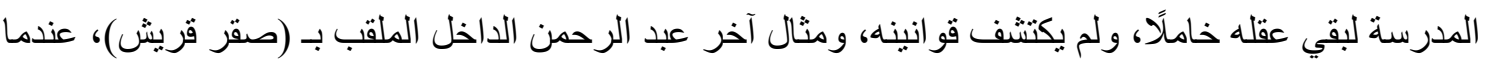

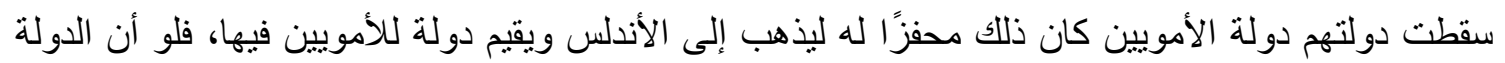
الأموية لم تسقط، لبقي عبد الرحمن الداخل في الثشام، ولم يُعمل عقله الخامل ليُفكر كيف يحكم الأندلس، فكانت المعاناة محفزًا لعمل العقل الخامل وتتشيطه، و على هذين المثالين فقس. 
الهجلة الدولية لنشر البحوث والدراسات

International Journal of Research and Studies Publishing
المجلد الثاني - الإصدار الثامن عشر

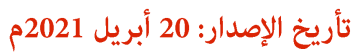

ISSN: 2709-7064

و الثكل التالي يُبيِّن كيف يعمل العقل الخامل:
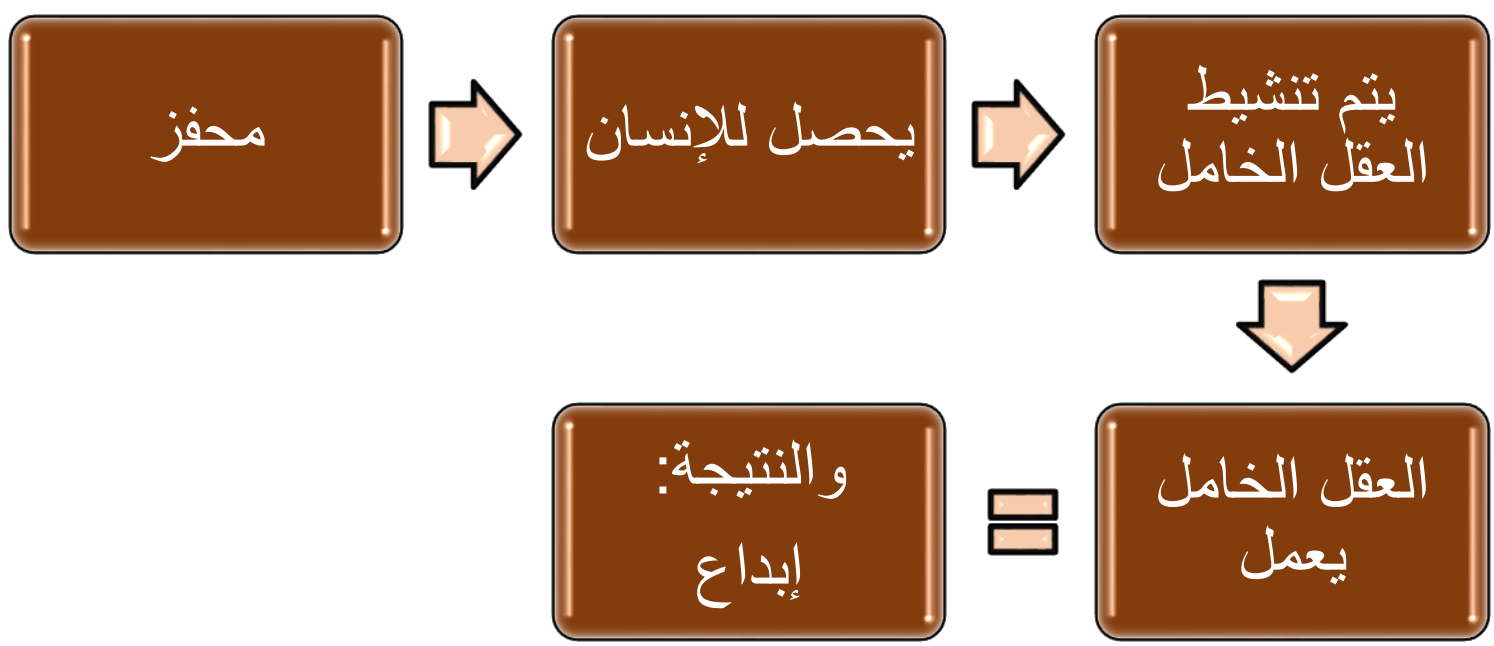

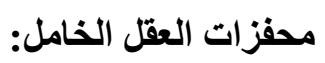

توجد ثلاث محفزات تحفز العقل الخامل للإبداع و الابتكار ، وهي كما يلي:

1) المعاناة: فالمعاناة التي يعانيها الإنسان تحفز عقله لكي يصل إلى سُبّل عيش أفضل، ويدخل في هذا المحفز كل معاناة يعانيها الإنسان من ظلل، أو فقر، أو ضعف، أو غير ذلك من أنواع المعاناة، وهذا كما حصل

$$
\text { لنيوتن، و عبد الرحمن الداخل، و غير هم. }
$$

2) الحاجة: وكما قيل قديمًا: "الحاجة أم الاختر اع". فإذا احتاج الإنسان لشيء صدارت هذه الحاجة محفز للعقل الخامل لكي يعمل، و هذا كما حصل في حياة الناس، فقد تطورت شينًا فشينًا حتى وصلت إلى ما نحن عليه اليوم، و السبب في ذلك هي الحاجة إلى هذه الاختراعات التي بسببها تصبح الحياة أسهل، ويدخل في هذا

$$
\text { المحفز رغبات الإنسان. }
$$

3) المنافسة: فهي تولّدّ عند الإنسان حب السيطرة و الفوز، فيكون ذلك بمثابة محفز للعقل الخامل لكي يعمل،

$$
\text { ويدخل في ذللك كل ما يدخل في المنافسة من الشعور بالضعف، أو الهزيمة، أو السخرية، }
$$

4) أو حتى حب السيطرة، أو الهيمنة، أو حب الغلبة، أو الطموح، ونحو ها فتعتبر كلها حو افز تحفز العقل الخامل،

و هذا كما يحصل بين الثركات، والمنافسة التي بينهم اليوم، فهذا منشط للعقل الخامل للعاملين في هذه

الشركات، وكذلك المؤسسات في ابتكار أفكار تكون سببًا في جودة المنتجات التي تعطيها ميزة على غير ها،

أو لتحصل على جائزة، ونحو ذلك.

5) المشكلة: فإذا حصلت المشكلة فإنَّها تحفز العقل الخامل لكي يعمل ليخرج الإنسان من هذه المشكلة. 
الهجلة الدولية لنشر البحوث والدراسات

International Journal of Research and Studies Publishing
المجلد الثاني - الإصدار الثامن عشر تأريخ الإصدار: 20 أبريل 2021م

ISSN: 2709-7064

هذه أربع محفزات تحفز العقل الخامل، أوضحها في الثكل التالي:

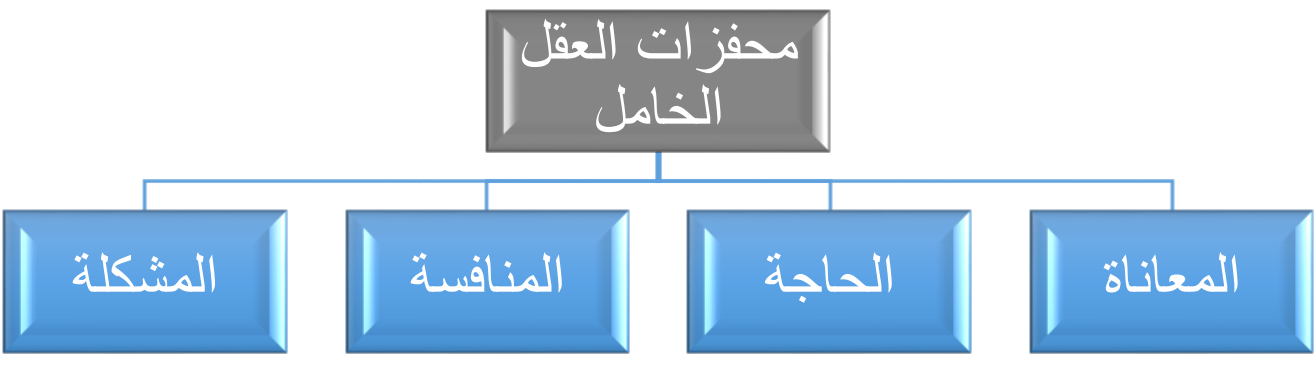

مقدار القدرات العقلية التي يستخدمها الإنسان في حالة عدم وجود المحفز للعقل الخامل:

إذا قلنا أنَّ وظائف العقل لكي يبتكر، ويبدع، هي: (الحفظ، التفكير، التحليل، الاستنتاج، و التصرُّ)، فكم من هذه الوظائف سيكون نشيطًا؟ وكم منها سيكون خاملًا؟ فإذا كان الإنسان يعيش حياته بشكل طبيعي ولديه روتين محدد يسير عليه، من المنزل إلى الدوام إلى الترفيه و هكذا فإنَّه يستخدم و احدة من قدر اته العقلية وهي (التصرُّف) فقط، ولكنه لا بستخدم بقية وظائف عقله، فبالتالي هو يستخدم فقط (20\%) من قدر اته العقلية، وذللك لأنَّنا إذا قسمنا قدر ات عقل الإنسان فإنتَّا نقسم 100٪5= 20، و والخمسة هي وظائف العقل، والمئة هي قدرات عقل الإنسان مجتمعة، فالإنسان في حياته الروتينية يكون (80\%) من قدر اته العقلية خاملة، حتى يأتي واحد أو أكثر من محفزات العقل الخامل لكي ينشط هذه القدرات،

وفي الثكل التالي أبين مقدار القدرات العقلية المستخدمة في الحياة الروتينية:

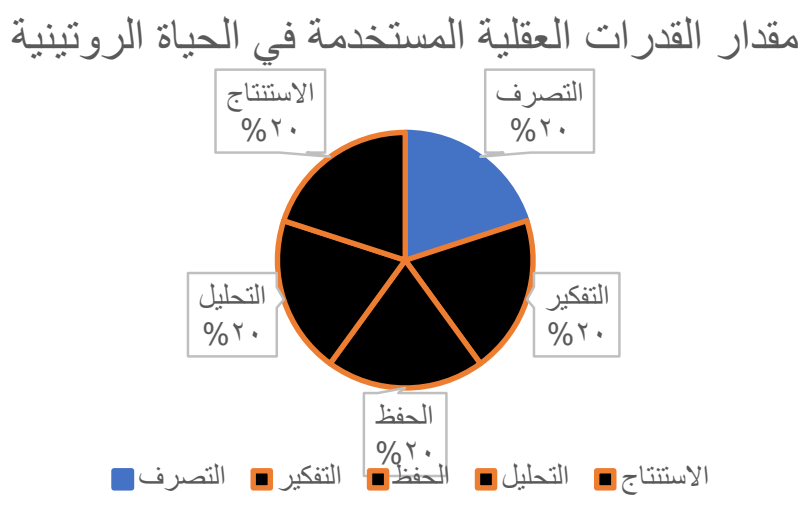


الهجلة الدولية لنشر البحوث والدراسات

International Journal of Research and Studies Publishing
المجلد الثاني - الإصدار الثامن عشر تأريخ الإصدار: 20 أبريل 2021م

ISSN: 2709-7064

فنلاحظ من خلال الثكل السابق أنَّ القدرات العقلية للإنسان لكي يبتكر تكون معطلة في حياته الروتينية، حتى يأتي المحفز فتبدأ وظائف العقل تتنشط، و هكذا، فكل وظيفة يستخدمها الإنسان يتنشط من القدر ات العقلية بمقدار ها، و هكذا.

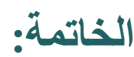

$$
\text { نتائج البحث: }
$$

نستنتج من هذا البحث ما يلي:

1) أنَّ الإنسان يستطيع أن يدرك الأمور الغيبية وغير المحسوسة بو اسطة عقله الخامل، وذلك من خلال تنشيط

$$
\text { هذا العقل من خلال (مقياس بيان الحقيقة من الوهم). }
$$

2) أهمية تنشيط العقل الخامل عند الإنسان، فهو يجعله يدرك الأشياء التي لا يمكن له إدر اكها بالوسائل الحسية

$$
\text { سواءً أكانت مجردة أم لا. }
$$

3) أنَّ تنشيط العقل الخامل عند الإنسان يستطيع من خلاله التفريق بين الحقيقة و الوهم.

4) أنَّه يمكن ضبط محفز ات العقل الخامل عند الإنسان.

5) أنَّهُ يُمكن التنبؤ بالسلوك البشري بالتعرُّف على محفز ات العقل الخامل.

$$
\text { المراجع }
$$

ـ بلكا، إلياس (2011). الغيب والعقل: دراسة في حدود المعرفة البشرية. إسلامية المعرفة. عرض الكتاب:

$$
\text { الجندي، محمد. المجلد17. العدد } 65 .
$$

- رضا، أمين (1975). تحكيم العقل. التوحيد. المجلد3. العدد 8-9.

- صوفي، عبد القادر (2003). العقل: تعريفه، منزلته، مجالاته، ومداركه. مجلة الحكمة. العدد 26.

ـ فايل، أريك (1981). العقل. مجلة الفكر العربي المعاصر. العدد 16.

Doi: doi.org/10.52133/ijrsp.v2.18.10 